\title{
Correction to: $p$-Hydroxy benzoic acid-conjugated dendrimer nanotherapeutics as potential carriers for targeted drug delivery to brain: an in vitro and in vivo evaluation
}

\section{Rajan Swami • Indu Singh • Hitesh Kulhari • \\ Manish Kumar Jeengar • Wahid Khan • \\ Ramakrishna Sistla}

Published online: 28 October 2017

(C) Springer Science+Business Media B.V. 2017

Correction to: J Nanopart Res (2015) 17: 265

https://doi.org/10.1007/s11051-015-3063-9

In the published manuscript https://doi.org/10.1007 /s11051-015-3063-9, a qualitative cellular uptake image in UT87MG cell line in Fig. 4c is incorrectly provided. The provided fluorescent images in Fig. 4 correspond to our other concurrent project on same cell line. So by an error the results were incorporated in as Fig. 4c. The corrected image is now provided as Fig. 4 without any change in caption. However, other

The online version of the original article can be found at https://doi.org/10.1007/s11051-015-3063-9

R. Swami · I. Singh · W. Khan $(\bowtie) \cdot$ R. Sistla

Department of Pharmaceutics, National Institute of

Pharmaceutical Education \& Research (NIPER),

Hyderabad 500037, India

e-mail: wahid@niperhyd.ac.in

H. Kulhari $\cdot$ R. Sistla $(\triangle)$

Medicinal Chemistry \& Pharmacology Division, CSIR-Indian

Institute of Chemical Technology, Hyderabad 500007, India

e-mail: sistla@iict.res.in

e-mail: rksistla@yahoo.com

\section{H. Kulhari}

IICT-RMIT Research Centre, CSIR-Indian Institute of Chemical Technology, Hyderabad 500007, India

M. K. Jeengar

Department of Pharmacology, National Institute of Pharmaceutical Education \& Research (NIPER), Hyderabad 500037, India result values such as receptor saturation assay (Fig. 4a) and quantitative uptake assays (Fig. 4b) proved the potential of the formulation, were correctly provided in figure as well as in text.

Hence, the incorrect value does not influence the general concept of the article, its other results or its conclusions, nor it demands an in-depth revision of the published text. 

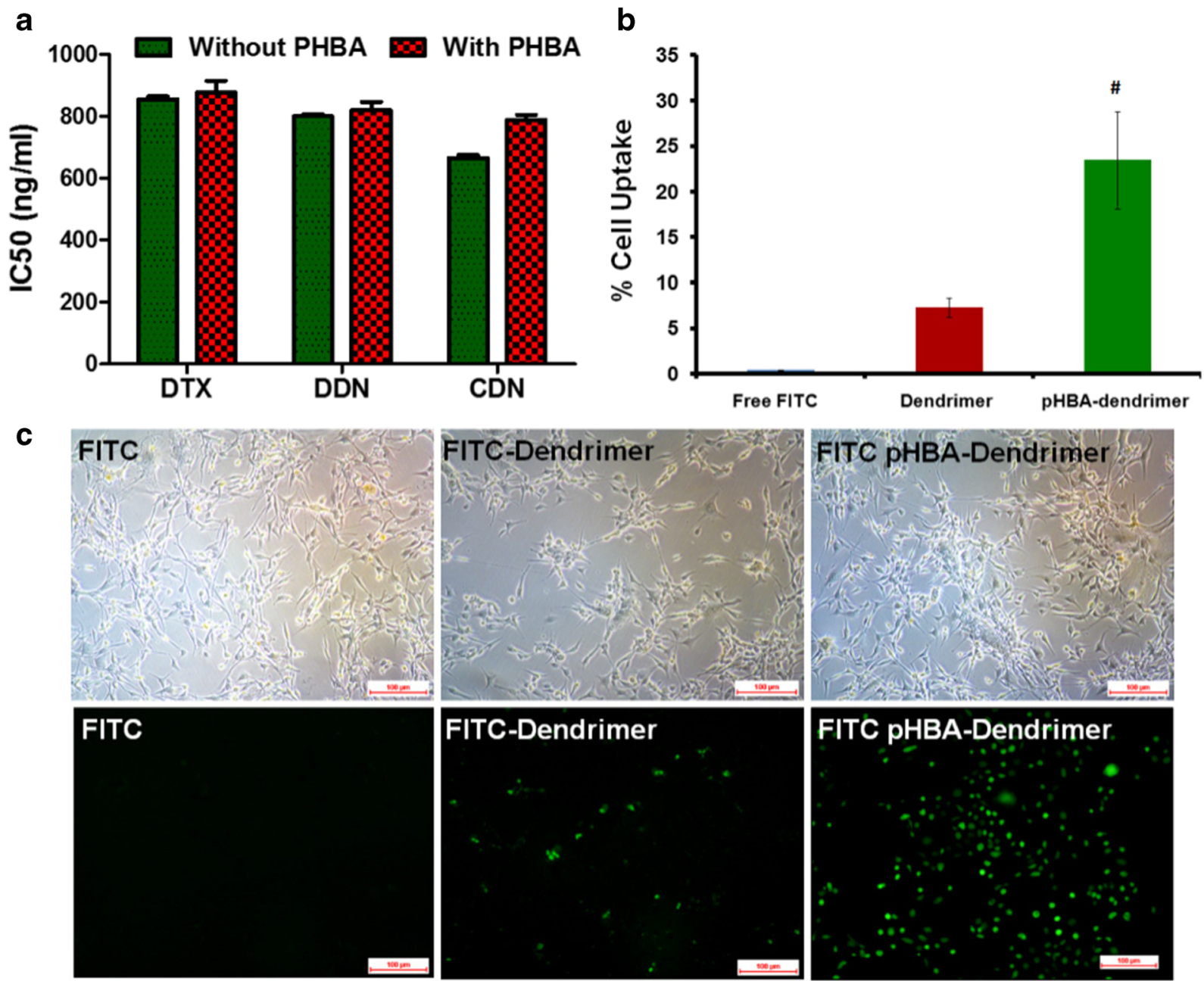

Fig. 4 Quantitative cytotoxicity and cell uptake studies. a Results showing graphical illustration of IC 50 values (mean $\pm \mathrm{SEM}, n=6$ ) of DTX (docetaxel solution), DDN and CDN obtained without pHBA saturation and compared to IC50 obtained after saturation of cell lines with free pHBA. b Graphical demonstration of quantitative cell uptake of DTX formulations after $2 \mathrm{~h}$, data represented (mean \pm SD). c Phase contrast (FITC, FITC-dendrimer and FITC
pHBA-dendrimer) and fluorescent (FITC', FITC-dendrimer' and FITC pHBA- dendrimer') cell uptake images indicating internalization of FITC tagged dendrimer formulations. pHBA-dendrimer formu- lation showed enhanced uptake as compared to unconjugated dendrimer and FITC control. ${ }^{*} P<0.05 \mathrm{CDN}$ versus DDN, ${ }^{\sharp} P<0.001$ pHBA-dendrimer versus dendrimer 